\title{
Esthetic Management of Maxillary Midline Diastema (MMD) Using Composite Restoration: A Case Report
}

Treatment of a Maxillary Midline Diastema (MMD) poses a challenge to the clinician, especially when time is a constraint. The use of composite resins provide a conservative approach with minimal tooth loss is less time consuming, and requires fewer dental visits. The present case report describes the closure of MMD in a patient using bulk filled composite resins with favourable results.

KEYWORDS: Maxillary Midline Diastema (MMD), Spacing, Closure, Esthetics.

\begin{abstract}
INTRODUCTION
Mildline diatsema, commonly called as Maxillary Midline Diastema (MMD), is a commonly seen esthetic problem which has a negative impact on the patient. The patient is afraid to smile, and can show traits of being shy as he/she is wary of the spacing between his teeth being seen the moment he speaks, smiles or eats. The spacing between the two maxillary teeth should be greater than $0.5 \mathrm{~mm}$ to be classified as MMD. ${ }^{1}$ The treatment mainly is due to esthetic and physiological reasons and not due to functional reasons, and requires different approaches by the clinician, thus necessitating the need for an interdisciplinary approach. ${ }^{2}$ While an orthodontic treatment can be time consuming, careful consideration is needed as orthodontic anomalies need to be treated first before the diastema can be treated, so that the occlusion of the patient is not hampered and a functional aim is achieved.
\end{abstract}

Less time consuming procedures for treatment of MMD include the use of laminates/veeners, crowns and composite build up. While the use of crowns/ laminates and veeners are a desired treatment modality, the use of composite build-up is said to be a treatment option desired by many, especially, in which time is a constraint as the use of crowns and veneers require the need of crown cutting which is not preferred by many patients.

The option of using composites for treating MMD is the use of a conventional approach, as described above. MMD closure by composites is a safe, fast technique, and requires no cutting of the tooth structure. The composite is bonded to the tooth structure using simple etching technique. ${ }^{3}$ The present case report describes a patient, whose midline diastema was treated using conventional composite treatment with favourable results.

\section{CASE DESCRIPTION}

A 25 year old patient, recently came to the dental clinic with a complaint of spacing between $(\sim 5$ $\mathrm{mm}$, Figure. 1) in his front two teeth, and wanted to get them treated as he was getting married within a month. Since time was a constraint and intra-oral examination showed no need for an orthodontic treatment, hence a conventional treatment of the MMD using bulk composite was decided upon after scaling and polishing.

Shade selection was done using Ar shade of Vita guide for the teeth to be restored. And composite shade Ar (Dentsply, India) was chosen for the composite restoration. Prior to the commencement of the MMD closure, the maxillary incisors were isolated using a rubber dam. The central incisor adjacent to 21 was covered with Teflon band while the other was restored using a $37 \%$ phosphoric acid was applied on the mesial surface of 21, for 15 seconds, rinsed for 20 seconds, and dried with a slight blast of air. Following the etching, the miscroporosities were then bonded using an applicator tip and polymerized for 20 seconds with a LED light. The bulk composite was placed, shaped and cured accordingly. The same procedure was repeated for tooth number 21. At last, the composite was 
polished and the patient was contented with the results (figure 2). The entire procedure took around 1 hour to complete.

\section{DISCUSSION}

The present case, in which the MMD was treated within a time period of 1 hour using bulk fill composite resin restorations, which often do not require preliminary models or wax-ups, and do not involve laboratory fees that leads to escalated costs. The use of composite offers a conservative, time saving approach which ceramic veneers and orthodontic treatment do not have. They are kinder to the opposing dentition and in case of the event of an unforeseen fracture and can be repaired easily which saves precious time of the clinician and the patient. ${ }^{4,5}$

There are also some disadvantages of direct composite resin restorations compared to some indirect porcelain alternatives. Most composite materials possess less fractural toughness, shear, and compressive strength and are not ideally suited for ultra-high-stress areas found in certain clinical situations. ${ }^{6,7}$ Additionally, the presence of parafunctional forces such as bruxism, Class III end-to-end occlusal schemes combined with undesirable oral habits such as nail biting, consumption of abrasive food or materials, can substantially jeopardize the life-span of a direct composite restorations. ${ }^{8}$ Regardless of these disadvantages, the constant introduction of newer and more stable composite restorations give clinicians the chance to a perform substantially conservative, functional, aesthetic restorations within a short time frame and with desirable results.

\section{REFERENCES}

1. Keene HJ. Distribution of diastemas in the dentition of man. Am J Phys Anthropol. 1963;21:437-41.

2. Bernabe E, Flores-Mir C. Influence of anterior occlusal characteristics on self-perceived dental appearance in young adults. Angle Orthod. 2007; 77:831-6.

3. Dale BG, Aschheim KW. Esthetic Dentistry: A Clinical Approach to Techniques and Materials, vol. 11, Lea and Febiger, Philadelphia, Pa, USA, 1993.

4. Magne P, Belser UC. Porcelain versus composite inlays/onlays: effects of mechanical loads on stress distribution, adhesion, and crown flexure. The International Journal of Periodontics \& Restorative Dentistry 2003; 23(6):543-55.

5. Berksun S, Kedici PS, Saglam S. Repair of fractured porcelain restorations with composite bonded porcelain laminate contours. The Journal of Prosthetic Dentistry 1993; 69(5):457-8.

6. Korkut B, Yanikoglu F, Tagtekin D. Direct Midline Diastema Closure with Composite Layering Technique: A One-Year Follow-Up. Case Reports in Dentistry; 2016:6810984.

7. Nandini S. Indirect resin composites. J Conserv Dent. 2010;13(4):184-94.

8. Alharbya A, Alzayerb $\mathrm{H}$, Almahlawic A, Alrashidid Y, Azharc S, Sheikhod M, et al. Parafunctional Behaviors and Its Effect on Dental Bridges. J Clin Med Res. 2018;10(2):73-6. 
Source of support: Nil, Conflict of interest: None declared

\section{AUTHOR AFFILIATIONS:}

1. MDS (Public Health Dentistry), Private Practitioner.

\section{Cite this article as:}

Khan K. Esthetic Management of Maxillary Midline Diastema (MMD) Using Composite Restoration: A Case Report. Int Healthcare Res J 2018;2(3):63-65. doi: 10.26440/IHRJ/02_03/174

\section{Corresponding Author:}

Dr. Khateeb Khan

66-G, Sector 7

Jasola Vihar

New Delhi-110025
For article enquiry/author contact details, e-mail at: manuscriptenquiry.ihrj@gmail.com

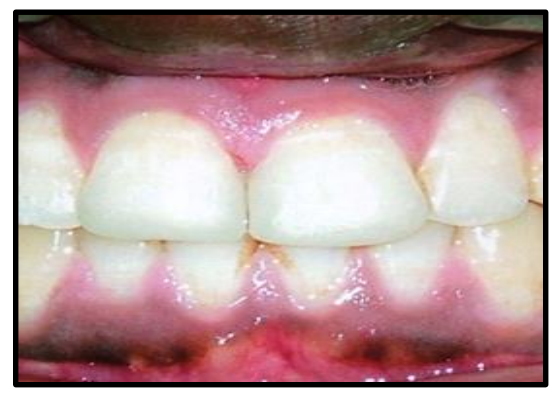

Figure 2: Post-operative Photograph Showing Favourable Results
Figure 1. Pre-operative photograph Showing Midline Diastema $5 \mathrm{~mm}$ 